\title{
Reducing Poverty-Related Disparities in Child Development and School Readiness: The Smart Beginnings Tiered Prevention Strategy that Combines Pediatric Primary Care with Home Visiting
}

\author{
Daniel S. Shaw ${ }^{1}$ - Alan L. Mendelsohn ${ }^{2} \cdot$ Pamela A. Morris $^{3}$ \\ Accepted: 24 August 2021 / Published online: 9 September 2021 \\ (c) The Author(s), under exclusive licence to Springer Science+Business Media, LLC, part of Springer Nature 2021
}

\begin{abstract}
This paper describes the Smart Beginnings Integrated Model, an innovative, tiered approach for addressing school readiness disparities in low-income children from birth to age 3 in the United States through universal engagement of low-income families and primary prevention in pediatric primary care integrated with secondary/tertiary prevention in the home. We build on both public health considerations, in which engagement, cost and scalability are paramount, and a developmental psychopathology framework (Cicchetti \& Toth, Journal of Child Psychology and Psychiatry, and Allied Disciplines 50:16-25, 2009), in which the child is considered within the context of the proximal caregiving environment. Whereas existing early preventive models have shown promise in promoting children's school readiness, the Smart Beginnings model addresses three important barriers that have limited impacts at the individual and/or population level: (1) identification and engagement of vulnerable families; (2) the challenges of scalability at low cost within existing service systems; and (3) tailoring interventions to address the heterogeneity of risk among low-income families. Smart Beginnings takes advantage of the existing platform of pediatric primary care to provide a universal primary prevention strategy for all families (Video Interaction Project) and a targeted secondary/tertiary prevention strategy (Family Check-Up) for families with additional contextual factors. We describe the theory underlying the Smart Beginnings model, some initial findings from its recent application in two cities, and implications for changing social policy to promote school readiness beginning during very early childhood.
\end{abstract}

Keywords Early childhood $\cdot$ School readiness $\cdot$ Parenting $\cdot$ Intervention $\cdot$ Pediatric care

\section{Introduction}

This paper describes an innovative, tiered approach for addressing school readiness disparities in low-income children from birth to age 3 through universal engagement of low-income families and primary prevention in pediatric primary care in the United States (Fletcher \& Fletcher, 2005) integrated with secondary/tertiary prevention in the home. Critical parenting characteristics and psychosocial

Daniel S. Shaw

danielshaw@pitt.edu

1 Department of Psychology, Dietrich School of Arts and Sciences, University of Pittsburgh, Pittsburgh, PA, USA

2 Grossman School of Medicine, New York University, New York, NY, USA

3 Steinhardt School of Culture, Education, and Human Development, New York University, New York, NY, USA stressors are addressed in this approach beginning during early infancy. We build on both public health considerations, in which engagement, cost and scalability are paramount, and a developmental psychopathology framework (Cicchetti \& Toth, 2009), in which the child is considered within the context of the proximal caregiving environment.

Existing models based in early childhood settings and/or utilizing home visitation (e.g., Early Head Start, Nurse Family Partnership, Parents as Teachers) have shown promise in promoting children's school readiness and improving parenting for children in the infant and toddler years. However, these models face three important barriers that limit impacts at the individual and/or population level: (1) identification and engagement of at-risk families; (2) the challenges of scalability at low cost within existing service systems; and (3) tailoring interventions to address the heterogeneity of risk among low-income families.

We address these barriers through a novel integration in pediatric primary care using two strategies shown to 


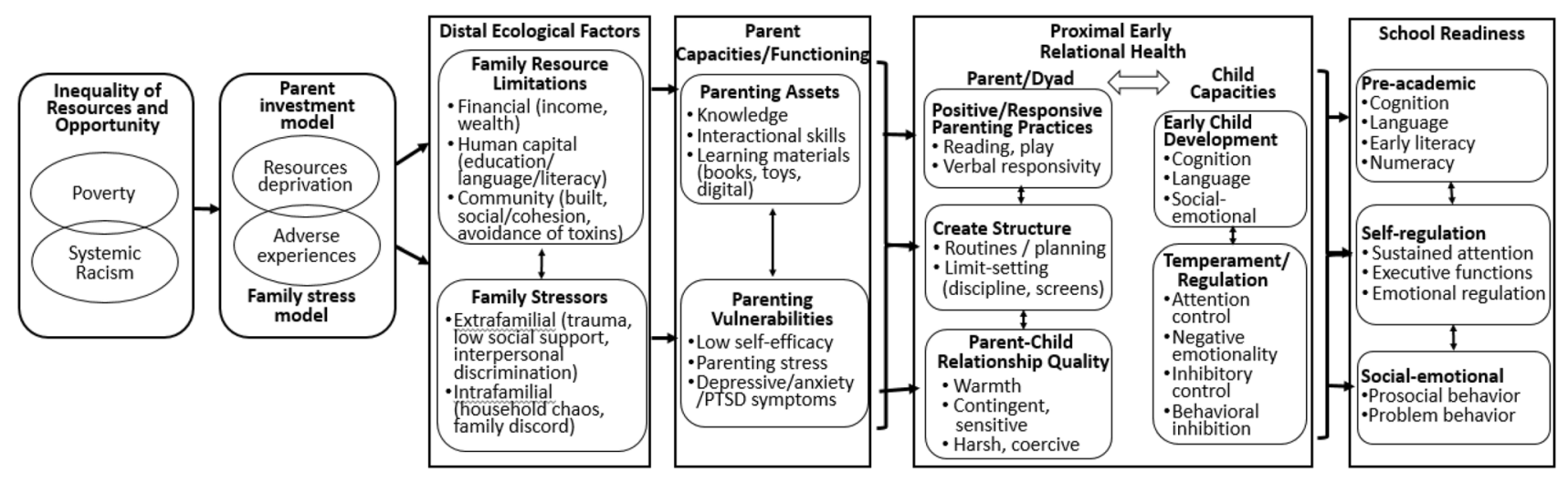

Fig. 1 Models and mechanisms by which poverty influences school readiness through early relational health

separately enhance early development and school readiness of children in poverty through support of positive parenting practices and reduction of the impact of psychosocial stressors: (1) a universal primary prevention strategy for all families [Video Interaction Project (VIP), Mendelsohn et al., 2005] that provides parents with an interventionist who video-records the parent and child and uses review of the video with the parent to support positive parenting, and (2) a targeted secondary/tertiary prevention strategy [Family Check-Up (FCU), Shaw et al., 2006], a home-based, familycentered intervention that utilizes an initial ecologicallyfocused assessment to promote motivation for parents to change child-rearing behaviors, with follow-up sessions on parenting and factors that compromise parenting quality for families with additional risks.

Our integrated model, called Smart Beginnings, has potential for population-level impact. Utilization of the pediatric platform for primary prevention (VIP) provides accessibility for primary prevention to low-income families beginning at a very young age with frequent contacts (13-15 recommended visits from birth to 5 years) and at relatively low marginal cost by building on existing infrastructure. Integration of home-based secondary/tertiary prevention (FCU) addresses the challenge of heterogeneity of risk through providing more intensive services for those with greater need. Furthermore, the integration of the two approaches provides synergies for identifying, engaging, and intervening with families. We are testing the Smart Beginnings model in two cities as part of a randomized trial funded by NIH/NICHD (R01HD076390)—early data show promise for both implementation and impact of our approach.

In this paper, we begin with a discussion of the "problem" that we are trying to address with this integrated modelpoverty-related disparities in school readiness and how they can be addressed through parenting interventions. We then discuss in more detail the barriers that our approach addresses (i.e., identification/engagement, scalability at low cost, and heterogeneity in risk) and mechanisms for achieving these aims. We end with a discussion of the opportunities for scale-up of the Smart Beginnings tiered approach across neighborhoods and cities. Note that we focus exclusively on the U.S. context in this paper, where the SB approach has been designed, although we suspect that there may be ways to adapt the SB model to other countries and contexts. We believe that our approach has the potential to be transformational (rather than incremental) in its approach to addressing school readiness disparities by providing a vehicle for promoting positive parenting beginning in the first months of infancy, most critically because of its commitment to population scalability that addresses key gaps largely unaddressed in early childhood research and policy.

\section{Poverty-Related Disparities in School Readiness}

As portrayed in Fig. 1, poverty-related disparities in early child development, school readiness, and educational achievement are well-documented (Duncan et al., 1998). The causal effects of low-income per se have been debated, but several studies demonstrate small, positive effects of income on children's outcomes using causal methodologies (Dahl \& Lochner, 2012; Duncan et al., 2011; Gennetian et al., 2010). Research suggests that poverty has the strongest detrimental effects early in life (Duncan et al., 1998; Hart \& Risley, 1995). Income-related disparities impact aspects of child development that are crucial for school readiness including: cognitive and language capacities (Dahl \& Lcohner, 2012; Milligan \& Stabile, 2011), emergent literacy and numeracy (Duncan et al., 1998; 2011), social-emotional development (Milligan \& Stabile, 2011), and self-regulation (Blair, 2010; Evans \& Kim, 2013; Hails et al., 2019). Together these domains form the core components of school readiness that 
are seen as critical for the transition to school and subsequent educational progress and achievement (Duncan et al., 2007; Romano et al., 2010). Studies suggest that more than half of children living in poverty lack such school readiness skills (Duncan et al., 1998; 2007). Systemic race-related disparities and stressors at individual (e.g., interpersonal discrimination; Brody et al., 2006; Desmond \& Emirbayer, 2009; Tomaskovic-Devey et al., 2005; Turner \& Skidmore, 1999), and community (e.g., structural racism—social and economic) levels (Altonji \& Blank, 1999; Bailey et al., 2017; Pachter \& Garcia-Coll, 2009) potentiate these poverty-related disparities. Additionally, developmental cascade theory suggests that in the early years of rapid brain development, small impacts consolidate into an increasing range of child and adolescent outcomes, including substance use, antisocial behavior, and internalizing problems (Dodge et al., 2009; Sitnick et al., 2015). Thus, there is a critical need for preventive interventions that target these disparities (i.e., poverty-related disparities, compounded by systemic racism) prior to their emergence, as doing so will have longterm implications across the lifespan.

\section{Early Relational Health: A Final Common Pathway}

Strong evidence suggests that parent-child early relational health-defined as positive/responsive parenting practices, creating/maintaining structure and parent-child relationship quality-represents a central mechanism by which poverty and related, compounding contextual risks (e.g., systemic racism in part acting through poverty) account for disparities in school readiness and long-term behavioral and academic trajectories (Duncan et al., 1998; Hart \& Risley, 1995; Ladd et al., 1999; Normandeau \& Guay, 1998). In particular, practices such as reading aloud (Hoff-Ginsberg, 1991; Neuman, 1991; Whitehurst et al., 1994, 1999), playing together (Bornstein et al, 2008; Harris, 2006), engagement in routines (Hale et al., 2009; Huttenlocher et al., 2010) and limit setting (Baumrind, 1971; Leve et al., 2009, 2010) benefit cognitive-language and social-affective interactions (Shonkoff, 2017) that support self-regulatory, pre-academic and social-emotional capacities underlying school readiness (Office of Head Start, 2017; Spoth et al., 2007; Tabors et al., 2001), whereas low levels of coercive and harsh parenting are similarly protective (Dishion et al., 2008).

An additional key concept not highlighted in these models is the recognition that children do not bring passive blank slates to early relational health. As first described in Bell's (1968) seminal description of reciprocal models of child development, then elaborated on by Sameroff and Chandler (1975), Patterson (1982), and others for specific types of problem behavior during early childhood (Scaramella \&
Leve, 2004; Shaw \& Bell, 1993), each aspect of early relational health is likely influenced by a number of partiallyheritable child temperament dimensions-some of which may also be affected by poverty- and racism-related stressors during the prenatal period. Accordingly, individual differences in such attributes underlying reactivity and regulation, including attentional control, negative emotionality, inhibitory control, and behavioral inhibition have been documented to have both direct effects on multiple dimensions of school readiness (Blair, 2002; Eisenberg et al., 2010; Hartz \& Williford, 2015; Razza et al., 2010), and influence how different dimensions of parenting are "received," influencing both relational health and pathways from relational health to school readiness (Liu et al., 2020; Shaw et al., 1998; Sitnick et al., 2015; Tiberio et al., 2016). Hence, as evidence suggests that children are active participants in their socialization process in general and the formation of relational health in particular, these child factors are incorporated into Fig. 1. Anecdotally, it would be easy to imagine an overly inhibited child eliciting high levels of parental intrusive behavior, and children with low levels of inhibitory control prompting higher levels of parenting structure and in extreme cases, harsh discipline. Empirically, using a genetically-informed study of adopted children, Leve et al. (2009) found that adoptive parents' greater levels of structure in a clean-up task at 18 months was effective in preventing high levels of concurrent child problem behavior, but only for children whose biological parents demonstrated high levels of psychopathology. For children whose biological parents demonstrated low levels of psychopathology, providing high levels of structure was associated with higher risk of subsequent disruptive behavior. Thus, while children with higher levels of biological risk might benefit from higher levels of parental structuring, the same parenting strategy might result in less adaptive outcomes for children at lower biological risk (i.e., less reactive and better regulated temperamentally). Coupled with several studies citing longitudinal transactional processes between parenting and dimensions of child temperament during early childhood, it is critical to incorporate child attributes into developmentally informed models of school readiness.

\section{Preventing Poverty-Related Disparities through Supporting Early Relational Health}

Consistent with models of equifinality that emphasize multiple types of risk factors leading to similar maladaptive child outcomes (Cicchetti \& Rogosch, 1996), early relational health as a convergent outcome of both the investment and family stress pathways points to its salience as a target of early intervention (Landry et al., 2006, 2008). However, recent research on interventions focused on relational health 
suggests that targeting positive aspects may be more effective than targeting negative ones. More specifically, recent longitudinal analyses have demonstrated that positive practices such as being sensitive to infant cues and reading aloud are associated with reductions in coercive interactions (e.g., harsh discipline) (Jimenez et al., 2019) and even may prevent antecedent psychosocial risks such as stress (Canfield et al., 2015, 2020a, b; Cates et al., 2016a, b; Weisleder et al., 2019) and depressive symptoms (Berkule et al., 2014). For example, using a cross-lagged model based on annually-observed parent-child interaction at ages $2,3,4$, and 5 with 731 lowincome, parent-child dyads, Sitnick et al. (2015) found consistently significant cross-lagged paths from positive dyadic interaction to lower levels of coercive interactions from ages $2-3,3-4$, to $4-5$, all paths of which were nonsignificant from coercive dyadic interaction to positive interactions. In the same vein, Weisleder et al. (2016) and Mendelsohn et al. (2018) found that impacts of an early relational health intervention on child social-emotional development were mediated by positive parenting activities (reading aloud, play and routines). Consistent with the tenets of social learning theory (Patterson, 1982), these findings suggest that although both low levels of positive interactions and high levels of negative dyadic interactions contribute to challenges in children's school readiness, increasing positive parenting appears to be the preferred choice for early prevention programs.

In addition to highlighting the importance of parent-child relational health, for highest risk families, longitudinal findings suggest the need for reducing exposure to psychosocial stressors in the family environment (e.g., parental depression, parenting stress, marital discord) that occur more frequently in the context of poverty (Belsky, 1984; Shaw et al., 2000; Taraban \& Shaw, 2018). These stressors individually and cumulatively increase risk of suboptimal school readiness across domains by creating barriers to providing contingently responsive and structured caregiving environments (Emery, 1988; Patterson, 1982; Shaw et al., 2009). Theoretically, reducing the intensity of family stressors that compromise parenting quality should improve the quality of caregiving, supporting parents' ability to be more psychologically available when interacting with their young children and more active in planning activities and obtaining resources for promoting their children's psychosocial development.

\section{Barriers to Reducing Poverty-Related Disparities}

A wide range of intervention programs have sought to prevent school readiness disparities by promoting relational health and attenuating effects of psychosocial stressors.
While there is significant evidence of efficacy of programs at the individual child level (e.g., HomVEE et al., 2020) and there have been some population-level effects on parent investment/positive parenting (Shonkoff, 2017), impacts at the population level on school readiness have been surprisingly limited given decades of attention and investment of sizeable research dollars (Greenberg \& Abenavoli, 2017; Isaacs \& Roessel, 2008). These models face three important barriers and challenges that have severely limited impacts at the population level:

(1) Identification and engagement of low-income parents

Identification and engagement of low-income parents of infants/toddlers, including recruitment and retention, represent a long-standing challenge for early childhood interventions, especially for parents of infants and toddlers for whom there are fewer universally-accessed systems (i.e., schools). Family-centered interventions often struggle to identify settings that are already frequented by large numbers of families and thus where large percentages of economically-challenged families can easily be reached and offered interventions. This issue is exacerbated by the fact that most programs, including evidence-based preventive interventions, access families through a single access point (e.g., school, home), prohibiting identification of families who do not use this access point because of language or other barriers. In addition, engaging in such programs may represent a significant challenge in terms of accessibility based on the many demands faced by families in poverty (e.g., working multiple jobs, traveling long distances for work or child care). Further complicating the identification challenge is a prevention program's ability to engage families, which is highly dependent on the convenience of using the program. There is likely to be considerable heterogeneity across families, with variation in preference for time and location of intervention delivery, with some families preferring clinical settings where they already will be, and some families preferring delivery in their homes or other accessible locations (e.g., libraries, family support centers). Key barriers to engagement include logistical issues (e.g., time, transportation) exacerbated by work force participation and attitudes regarding preventive strategies (Spoth et al., 1996, 2007). With all of these barriers, it should not be surprising to learn that only approximately $40 \%$ of families invited to enroll in home visiting programs do so (Bower et al., 2020), with $80 \%$ of families receiving less than the intended number of offered visits (Sparr et al., 2017). As an example, it is estimated that only $1 / 3$ of Early Head Start families complete the program (Isaacs \& Roessel, 2008). 
(2) Cost and potential for scalability in existing service systems.

Existing programs for infants and toddlers cannot easily utilize platforms that support population-level impact (e.g., public school systems), in large part because such universal platforms do not exist during very early childhood. Importantly, from a prevention science standpoint, existing approaches are typically very expensive whether located in the home (e.g., \$3750/family/year for ParentChild +; Levenstein et al., 2002; Hom VEE, 2020) or centerbased (e.g., \$10,500/child/year for Early Head Start), making scalability fiscally challenging and population-level impact unlikely. For instance, while Early Head Start (that includes both a center-based and a home-based option) has been shown to significantly impact children's cognitive and social-emotional development (Love et al., 2005, 2013), the program reaches only $11 \%$ of eligible families (or 160,000 children; National Head Start Association, 2021a, b. Home visiting programs such as Nurse Family Partnership, Parents as Teachers, and Healthy Families America (Harding et al., 2007; Olds et al., 1998; Wagner et al., 2002) have been widely disseminated and have favorably impacted maternal-infant health, family relational heath, and school readiness (Olds et al., 1986, 1998). Although such programs have quadrupled the number of families served recent years to reach approximately 300,000 families (including families served by the home-based version of Early Head Start that comprise about a third of Early Head Start families; National Home Visiting Resource Center, 2020), unmet need remains-home visiting programs current capacity is estimated at $2 \%$ of families that could benefit, with cost a key contributor.

\section{(3) Heterogeneity of risk.}

There is substantial heterogeneity in $\mathrm{SDoH}$, parent assets and vulnerabilities, parent-child early relational health, and even child school readiness outcomes in low-income households (Mohajer \& Earnest, 2010; Young, 2014), as well as in frequency of adverse outcomes across all levels of contextual and psychosocial risk. Such heterogeneity suggests the need for strategies that are tailored and targeted toward the specific parenting issues and stressors relevant to individual families and their contexts, and linked to specific school readiness outcomes. Also, based on a growing scarcity of resources, a challenge for the service community is effectively identifying those families who are at risk as well as those who can maximally benefit from various components of an integrated, tiered prevention model. While existing family-centered interventions have tended to address parenting issues broadly and follow a regimented protocol, an emerging body of intervention work has begun to consider and address heterogeneity by aligning services with family and community needs. For example, the Family Connects postnatal home visiting model (Dodge et al., 2014; Goodman et al., 2019) utilizes a variety of screening approaches to facilitate connection of families to community resources during early infancy. In the pediatric health care setting, HealthySteps co-locates a mental health provider who facilitates practice-level screening/referral for SDoH and provides mental health services for parents (Minkovitz et al., 2003, 2007). Similarly, each of the two interventions comprising our tiered model (discussed in more detail in the next section), VIP and FCU, tailors interventions to family strengths and goals; both use videorecording with feedback and planning to facilitate flexibility in intervention delivery. Additionally, FCU uses an assessment battery to comprehensively engage families around their own specific needs and motivate families to change their approaches to parenting.

As noted above, comprehensive reduction in disparities is most likely to be successful if it offers services prior to emergence of risks and challenges (i.e., primary prevention) in addition to following their emergence (i.e., secondary/ tertiary prevention). A primary prevention approach is especially applicable for challenges in relational patterns, which theoretically could be sustained over time and lead to positive cascading impacts on multiple domains across the life course. In addition, a primary prevention approach is far less costly than treatment (Dalziel \& Segal, 2012; Ramos-Gomez \& Shepard, 1999), as providing specialized resources for implementation for an entire low-income population would be overly costly and overkill for many low-income families at the lower end of the risk continuum. For example, in a low-income sample of 731 WIC families, half of whom were randomly assigned to FCU (secondary/tertiary preventive intervention), using latent class analysis, Pelham et al. (2017) found substantial differences in treatment response on later child conduct problems based on the risk status of families at child age 2 . For low-income families with limited family stressors (other than single parenthood), effect sizes of the FCU were negligible on child conduct problems from ages 3 to 5 . But for those low-income families with a history of parental psychopathology (i.e., depression, antisociality), large family size, history of mental health treatment, and/or a history of contact with child welfare, effects sizes ranged from 0.63 to 0.82 . In short, FCU may not be an optimal intervention for reducing early child problem behavior for lower risk low-income families, while it may be quite effective for higher risk low-income families. These results reinforce the need for offering multiple preventive approaches to meet the heterogeneity of challenges faced by low-income families. However, to our knowledge no model has comprehensively integrated primary and secondary/ 


\begin{tabular}{|c|c|}
\hline Barriers: & Addressed by: \\
\hline $\begin{array}{l}\text { Engagement } \\
\text { Scalability }\end{array}$ & $\begin{array}{l}\text { Identify families and engage in } \\
1^{\circ} \text { prevention in medical home } \\
\text { (VIP) }\end{array}$ \\
\hline $\begin{array}{l}\text { Heterogeneity } \\
\text { in Risk across } \\
\text { Time }\end{array}$ & $\begin{array}{l}\text { Integrated } 1^{\circ}+2^{\circ} / 3^{\circ} \text { prevention } \\
\text { (SB): } \\
\text { - Tailored to risk, building on goals } \\
\text { - Potential for additive and } \\
\text { synergistic impacts } \\
\text { - Annual assessment }\end{array}$ \\
\hline
\end{tabular}

Fig. 2 Barriers to population-level impact addressed by SB

tertiary prevention approaches, perhaps because of a dearth of predictive data on who will be at greatest risk for maladaptive outcomes and who will most benefit.

In addition to addressing the issue of heterogeneity of risk across families, it is also critical to address the fluidity of risk across child developmental stage and over time. As an example, parents who demonstrate contingent responsivity to support infant's needs during the first year may be less able to provide the requisite structure on children's behavior during the transition to toddlerhood (i.e., 18 months) when children become more physically mobile and risks in the home or community increase in the context of poverty and discrimination. Because of fluidity in both developmental and family contexts, there is a need to provide ongoing assessments of parent-child relational health during the birth to age 3 period, rather than only conducting one assessment of child functioning only during the infancy or only during the toddler periods. Indeed, while it has not garnered the same attention as research on poverty, there is substantial volatility in income level for families across time (Western et al., 2016) that likely has implications for family wellbeing and children's development (Hill et al., 2013) and further supports the case for repeated assessment and ongoing intervention.

\section{Addressing Barriers Using a Tiered Intervention Approach: The Smart Beginnings Model}

Based on the research on young children's risk for inadequate school readiness, what is missing is a way to reach, engage, and strategically and effectively intervene with large numbers of families in poverty during very early childhood. As shown in Fig. 2, our approach to achieving these goals addresses the barriers of engagement, cost, and heterogeneity and fluidity in risk and need, thus, for tailored, preventive treatment, with repeated assessments for risk across time.

\section{Smart Beginnings Approach for Addressing Barriers to Engagement and Cost}

We utilize pediatric primary care as a platform for intervention to meet challenges related to barriers to engagement and cost (Cates et al., 2016a, b). The use of pediatric primary care has three important advantages:

(1) Potential for population-level accessibility to lowincome families beginning at a very young age with frequent contacts and at relatively low cost.

Pediatric primary care has the potential to be a universal platform because of requirements for screening and immunizations prior to school entry, with 13 to 15 American Academy of Pediatrics (AAP) recommended preventive visits from birth through the age of 5 years (AAP, 2021). Improvements in access during the last 2 decades underscore this potential. Medicaid expansion and the State Children's Health Insurance Program have resulted in 95\% of children being covered and $\sim 60 \%$ of the remainder eligible for public insurance (Cohen et al., 2020; Kenney et al., 2016), in turn facilitating attendance at AAP-recommended visits. Although attendance is significantly lower for families receiving public insurance, visit attendance is still estimated conservatively at $40-80 \%$ across all visits through age 3 years (Wolf et al., 2018). Primary care also offers early and frequent contact with families, which translates to a high number of potential "doses" of primary care interventions.

In addition to providing access to otherwise difficult toreach population, health care interventions have potential for lower cost through leveraging of existing infrastructure and limiting need for additional caregiver/provider and family travel time. VIP, delivered at preventive visits, is estimated to have a marginal cost of $\sim \$ 200 /$ child/year (including staff, supplies, space and overhead). Although costs for FCU are somewhat higher $(\sim 600-700$ per year in nonresearch implementations, Kuklinski et al., 2020) because of the need to use interventionists with graduate-level clinical training, because of FCU's relative brevity (i.e., average of 3-4 sessions per year), costs are still much lower than other home-based programs. Cost considerations strongly support VIP's and FCU's feasibility for universal and selective implementation among low-income families within pediatric primary care. 
(2) Potential for enhanced parental engagement through medical home models.

Pediatrics has led the transition to a "Patient Centered Medical Home" (PCMH) model and team-based care (Asarnow et al., 2017; Doyle et al., 2019; Kazak et al., 2017). PCMH is a multidisciplinary team approach in which psychosocial factors related to health and prevention are prioritized, accessibility, coordination and effective communication are emphasized, relationships are actively built with parents, and patient involvement in therapeutic plans is encouraged (AAP, 2021). Resulting enhancements in engagement have been shown to improve attendance and medical outcomes (Ashby et al., 2019; Dudek et al., 2018; Justvig et al., 2017; Limbers et al., 2020). Recognition of PCMH status for clinical sites through the National Committee for Quality Assurance (NCQA; www.ncqa.org/pcmh), in the context of a broad range of recent quality initiatives (New York Department of Health, 2021), provides strong support for PCMH practices. The PCMH model provides an infrastructure for implementation of complementary VIP and FCU strategies (e.g., relationship with interventionist, motivational interviewing; see below), with potential to facilitate engagement and scalability.

(3) Opportunity to build on already-existing preventive interventions and related infrastructure.

More than thirty years of pediatric initiatives to enhance school readiness in low-income families have resulted in both infrastructure and stakeholder buy-in that can support layering of models such as SB. Reach Out and Read (ROR), the longest-running such program, is well-aligned with the principles described above. Specifically, ROR promotes early relational health and school readiness through provision of children's books and guidance for parents at each pediatric health care visit. ROR's model has been shown to have clinically important impacts on both reading aloud and on child development (Klass et al., 1999; Mendelsohn et al., 2001; Needlman et al., 2005; Perlman et al., 2012; Zuckerman, 2009), and VIP was originally developed as an enhancement to ROR. ROR has been widely scaled, with 6,100 sites across the US serving 4,500,000 young children per year, representing approximately one quarter of birth to 5 year-old children living in low-income households (Reach Out and Read National Center, 2021). Most importantly for SB and other models with similar objectives, ROR has developed both central (ROR National Center) and regional infrastructure (35 regional and statewide affiliates) for delivery and training (33,000 providers/medical champions trained to date). This infrastructure has tremendous potential to support layering complementary preventive interventions such as SB to further enhance impacts in pediatric

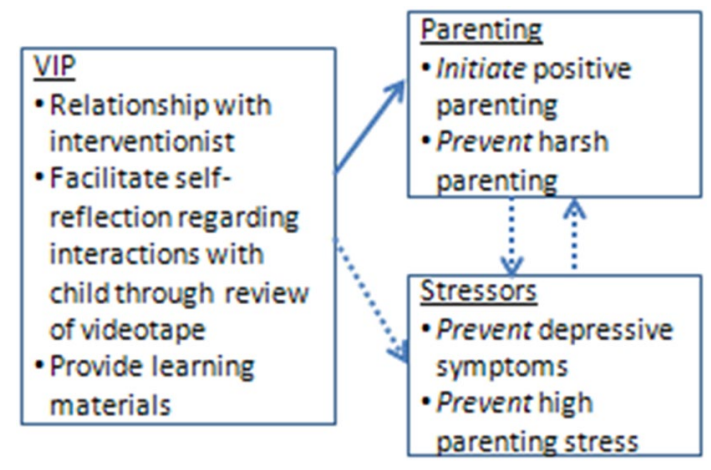

Fig. 3 VIP model for $1^{\circ}$ prevention in medical home prior to onset of family/child problems



Fig. 4 FCU model for $2^{\circ} / 3^{\circ}$ prevention of emergent family/child problems identified in VIP/medical home and addressed during home visits

primary care in clinical sites where buy-in has already been established (High et al., 2000; Reach Out and Read National Center, 2021). A second and more recent model, Healthy Steps (HS), provides an additional and similar opportunity for layering of complementary programs in pediatric health care building on infrastructure through Zero to Three that has been developed to support population-level expansion (Healthy Steps, 2021). As a result of these expansion efforts, HS currently reaches approximately 325,000 children in 189 sites across 24 states, DC and Puerto Rico, and 274 Healthy Steps Specialists have been trained to date (Briggs, 2021).

By capitalizing on the accessibility of pediatric primary care, VIP interventionists have been quite successful in initially engaging families and maintaining engagement in VIP during children's first year. Of six possible VIP visits in the first year that coincide with child well check-up visits, more than three-fourths of families attended five or six sessions, with less than $3 \%$ of families not having any VIP visits in this period. In addition, and consistent with the premise that VIP might be able to engage higher risk families within the context of pediatric primary care, participation in SB has been highest among mothers with lower levels of education 


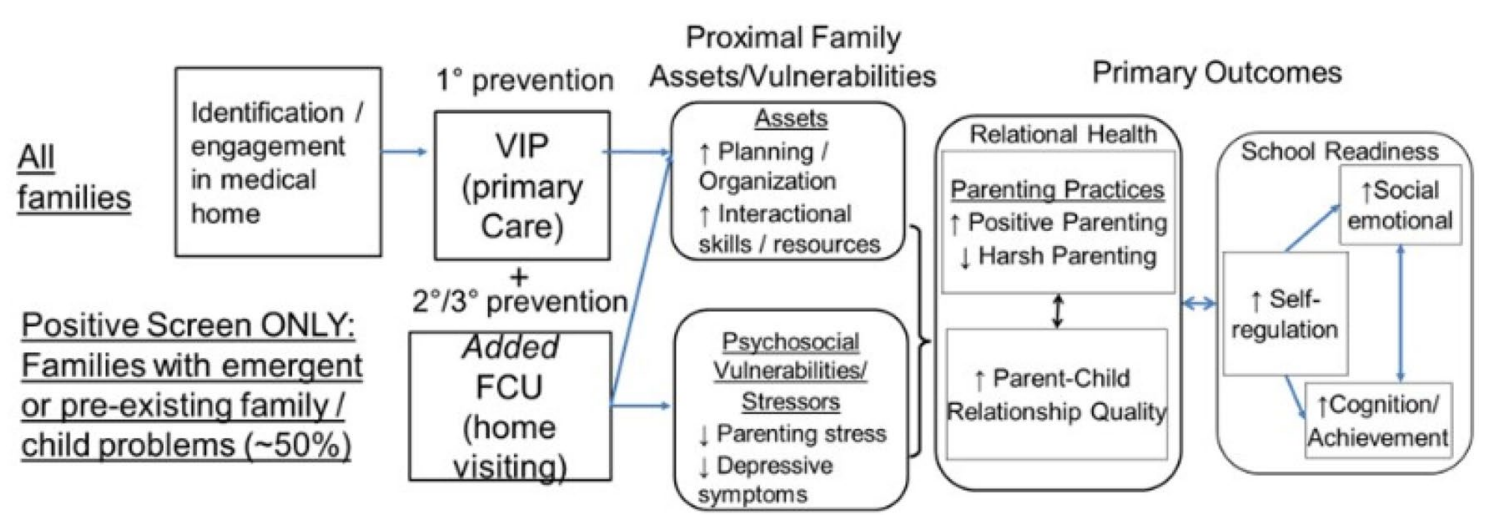

Fig. 5 Population-level conceptual model: SB tiered intervention, mechanisms of action

and lower reported parenting self-efficacy-those who have been hardest to reach in the context of preventive interventions (Miller et al., 2020).

\section{Smart Beginnings Approach for Addressing Challenges of Heterogeneity in Risk}

As displayed in Figs. 3, 4, we address challenges of heterogeneity in risk through the innovative, tiered integration of health care-based primary prevention with home-based secondary/tertiary prevention. VIP, the primary prevention program, utilizes pediatric well-child visits to build a relationship with a Bachelor's level interventionist who facilitates self-reflection regarding interactions with the child through review of video-recordings of the parent and child made that day, and further facilitates interactions through provision of learning materials (toys and books). VIP's focus throughout is on reinforcing positive parenting and strengths within the interaction. In the SB approach, VIP is offered universally at clinical practices serving low-income families regardless of their parenting assets and vulnerabilities, based on considerations related to equity, engagement (i.e., by not stigmatizing families at greatest need), and buy-in from the policy community and the public. This approach is aligned with the approach taken by ROR and AAP recommendations.

FCU (Fig. 4), the secondary prevention program, utilizes home visiting to build a relationship with a clinicallevel interventionist (Master's level) who assesses family strengths and challenges and incorporates motivational interviewing and evidence-based family management strategies to support parent and child behavioral change. As with VIP, FCU's impacts are primarily through the promotion of positive parenting and early relational health rather than the reduction of negative parenting. However, as FCU provides additional impact across a broad range of poverty-associated, and contextually-derived psychosocial stressors (e.g., depression, social support, family conflict), intervention effects on school readiness outcomes have been shown to be mediated by improvements in these stressors more broadly in addition to improved early relational health. Relatedly, targeting parent-child relationship challenges identified during the assessment process has been shown to improve satisfaction of parent social support. In the integrated model ("VIP/FCU"; Fig. 5), VIP is provided universally for all lowincome families with infants/toddlers to prevent the onset of problems by improving early parenting skills, while FCU is selectively provided to the subset of families with additional or emergent problems related to the family (parental depression, stress), the dyad (quality of parent-child interaction), and the child (language, self-regulation).

Notably, the SB framework aligns directly with AAP policy (Garner \& Yogman, 2021), which defines primary prevention in this domain as promotion of safe, stable, nurturing relationships (SSNRs), highlighting promotion of positive parenting and including VIP as a practice-level example. In that same policy, the AAP defines secondary prevention as universal screening and addressing of barriers to SSNRs, which are core components of FCU, and further recommends working across sectors, directly aligned with SB and current initiatives for large scale implementation (i.e., The Pittsburgh Study, described below). Together, the tiered approach aims to reduce the impact of early relational health challenges that are emerging as a result of assets/vulnerabilities driven by contextual-level poverty and racism.

\section{Alignment of VIP and FCU within the SB Model}

In addition to VIP and FCU being complementary in their level of prevention (primary vs. secondary/tertiary as above), the two programs are well-aligned from programmatic, implementation, and cost perspectives:

From a programmatic perspective: (1) both use videorecording with feedback as a core strategy, (2) both bring a focus on positive parenting and strengths in early relational health, (3) both consider and support interactions in the context of SDoH (informally for VIP, comprehensively 
for FCU), and (4) neither has a set curriculum but instead builds on parent goals and needs enhancing engagement and allowing for tailoring of intervention to heterogeneity of assets and needs to meet the needs of individual families in the context of poverty. These last three components are especially important as they allow SB to align with family and cultural beliefs and values, and help buffer impacts of systemic racism on family functioning. VIP and FCU's shared primary focus on early relational health (regardless of $\mathrm{SDoH}$, and in the case of FCU as an opportunity to address $\mathrm{SDoH}$ ) is relatively unique, complementing a number of programs with a core focus on identification and addressing SDoH (e.g., Family Connects, Help Me Grow, Healthy Steps).

From an implementation perspective: (1) both can be delivered at any time to any family, without requiring that the family participate in a specific sequence of content delivery, thus facilitating participation, and (2) both work with families in the settings where they are most accessible, reducing programmatic burden, with VIP engaging families during already-attended well-child visits with trusted providers, and FCU engaging families in their homes or other locations convenient for the family (e.g., primary care, family support center, WIC, library). In addition, both models have a strong focus on fostering cultural competence in professional interactions, which may be an important factor in accounting for high levels of engagement across diverse populations (Canfield et al., 2020a, b; Miller et al., 2020). Furthermore, within the context of the pandemic, both VIP and FCU have been adapted for remote use with families.

From a cost perspective: (1) each individual component (VIP and FCU) is at the lower end among programs that provide 1:1 services to support self-efficacy, skills and motivation for behavior change, supporting scaling, and (2) population-level costs of the integrated SB model are also low because of the utilization of lower cost Bachelor's level coaches providing universal prevention through VIP, while reserving higher cost clinical-level staff in FCU for families with additional risks and challenges.

\section{Potential for Additive and Synergistic Effects of Integrating VIP and FCU}

In addition to better tailoring interventions to the heterogeneous challenges facing low-income families with infants and toddlers, the Smart Beginnings tiered model also offers the potential for providing additive and synergistic effects by integrating the use of VIP and FCU, in effect demonstrating the power of tiered and fully integrated prevention/intervention approaches. Whereas all families are offered VIP, only select families are offered FCU based on the results of screening criteria. In the Smart Beginnings RCT described below, a screen was generated from select measures administered at the 6- and 18-month follow-up assessments, including parent (e.g., depression), parenting (low involvement), and child (e.g., high negative emotionality) risk domains. More specifically, credibility of the FCU parent coach is enhanced by a warm handoff from the VIP provider, including having the VIP provider introduce the parent to the FCU parent coach. Contact between VIP and FCU providers also ensures consistency and continuity in treatment, as VIP interventionists can inform FCU interventionists about the focus of their work. Continued communication and collaboration between the FCU and VIP interventionists also may be especially important in cases where the parent has selected to engage in follow-up treatment sessions. Accordingly, the FCU interventionist can inform the VIP provider about the focus of these sessions and help reinforce parenting skills during VIP sessions.

Highly relevant from a policy perspective, the opportunity provided for coordination together with the complementarity between the two models has enhanced program engagement. This positive collateral effect is particularly important based on the potential for overwhelming parents with multiple providers and interventions, with emerging findings in suggesting beneficial effects resulting from the integration. Program-specific engagement in both VIP and FCU within the SB integrated model is comparable or better than that for previous trials of each program individually during the infant and/or toddler periods. In addition to higher levels of engagement for VIP than in prior trials (described above, Miller et al., 2020), engagement in FCU within SB has been comparable to prior studies of FCU alone, with, 65\% overall (68\% in Pittsburgh, 62\% in NYC) of families being offered FCU engaging in the intervention at 6 and/or 18 months, meeting FCU's threshold of attending at the initial interview and feedback sessions (Dishion et al., 2008). Most importantly, preliminary data suggest that those intervention families who engage in FCU after VIP are more likely to engage in future VIP sessions than those FCU-eligible families that do not engage in FCU (Canfield et al., 2020a, b).

\section{The Smart Beginnings Randomized Controlled Trial}

For the past 5 years, we have been testing the integrated SB model in pediatric primary care in an NICHD-funded (R01HD076390) randomized controlled trial (half randomized to the integrated Smart Beginnings model, half to usual care) including 403 low-income families living in two cities, New York City and Pittsburgh, PA. Critically, testing our approach in these two cities positions Smart Beginnings well for dissemination-optimally balancing a strong test of efficacy while supporting next-stage effectiveness. As one of the greatest challenges of going from efficacy to effectiveness is diffusion of implementation quality and 
dilution of effect sizes (Dearing, 2008; Ghate, 2016), the current design allows us to maintain some initial control over quality by implementing one component of the intervention model under the direction of the PI who originally tested the model (VIP, under the direction of PI Mendelsohn in New York; FCU under the direction of PI Shaw in Pittsburgh), and allows for the testing of the other component of the model (FCU in New York; VIP in Pittsburgh) at a remote location. Moreover, the Smart Beginnings Project has allowed us to examine the integration of VIP and FCU in two different pediatric primary care clinics with different populations served. Although the samples are similar in terms of having few economic resources, they vary considerably in terms of ethnicity/race (i.e., in NYC sample is $84 \%$ Latinx, in Pittsburgh sample is $81 \%$ Black/African American) and family structure (i.e., at NYC $81 \%$ of parents were married or cohabitating vs. $40 \%$ in Pittsburgh). Such diversity in clinics' previous use of the interventions and family background characteristics has allowed us to look at similarities and potential differences in rates of engagement in VIP and FCU across settings.

Follow-up assessments have been conducted on the NYC and Pittsburgh samples at child ages 6, 18, and 24 months, with age 4 and 6 assessments ongoing. 6-month findings from the Smart Beginnings trial have been published (Roby et al., 2021, AAP, 2021), and show increases in cognitive stimulation (including reading and teaching) based on both survey and observational measures in New York City and Pittsburgh. While these findings are early in the study prior to FCU initiation and therefore necessarily reflect only VIP, they are nonetheless important in showing generalizability of previously shown impacts of primary prevention across site and race/ethnicity, and following implementation at a site distant from that of the original program developers.

\section{Next-Stage Implementation of Smart Beginnings: The Pittsburgh Study}

Although there are many merits of offering VIP and FCU as a tiered model within pediatric primary care, scaling the tiered model to a broader set of platforms may also be important to meet population-level goals. Indeed, this work is occurring in the context of The Pittsburgh Study (TPS). TPS is designed to meet the needs of a wider range of families, some of whom may require less or more intensive intervention and/or may not find program delivery to be optimally accessible or desirable delivered in-person in pediatric primary care or at their home. Funded primarily by the Children's Hospital Foundation of Pittsburgh, the University of Pittsburgh, Allegheny County's Department of Human Services, and several local foundations, the Early Childhood Collaborative of The Pittsburgh Study is a population-level implementation of programs with different levels of prevention and intensity, offered across multiple levels of care from multiple platforms to address the heterogeneity of risk among families. A primary goal of TPS is to see whether engagement in evidence-based early intervention programs can be increased by enhancing their accessibility to families. Thus, interventions are being offered at locations commonly frequented by low-income families with young children, including family's residences, pediatric primary care and FQHCs, WIC, family support and early learning centers, and libraries. If successful, improvements at the population level should be detectable in children's school readiness (and eventually reading scores in middle childhood) and rates of child maltreatment. Again, if successful in improving rates of engagement and demonstrating impact on children's outcomes, findings from TPS could inform changes in social policy to make evidence-based interventions more accessible within counties in the US.

Approximately 8000 families with children from birth through 4 years are being enrolled in-person or remotely (i.e., during the pandemic) at health care and other community settings described above, with families receiving a comprehensive screening assessment every 6 months from 0 to 3 years and annually from ages 3 to 4 . Following each screening, families are offered two or more evidence-based preventive programs based on identified strengths and challenges. For the majority of low-income families, the core primary prevention program will be VIP and the core secondary prevention program will be FCU, with more intensive programs (e.g., Healthy Families America, VIP and FCU together) and less-intensive (i.e., interactive and noninteractive texting programs) options also offered. Implementation commenced during the COVID-19 pandemic, with all interventions, including VIP and FCU, delivered through remote adaptations that build on family capacities and needs. Early data based on the first 450 families with infants enrolled suggest that approximately $76 \%$ of parents engaged in at least one of two interventions offered, with rates of engagement slightly higher-above $80 \%$ - for primary and secondary caregivers (e.g., mothers, fathers, grandparents) reporting clinical rates of depressive symptoms.

\section{Implications of Smart Beginnings: The Broader Context and Possible Future of Multi-level, Multi-platform Early Child Development and School Readiness Initiatives}

In this paper we have described the potential afforded by a multi-level and multi-platform program to promote child development and school readiness for young children living in the context of poverty. Historically, some holisticallyoriented prevention programs initiated during the prenatal 
period or infancy have attempted to address many facets of the stressors associated with poverty, including parenting (e.g., Family Connects, Nurse Family Partnership, Healthy Families America, Early Head Start, Family Spirit, Child First) (Morris et al., 2015; National Academies of Sciences, Engineering, \& Medicine, 2016). However, scalability remains a major challenge for such programs to have impact at the population level. Moreover, as these individual programs are a "one size fits all" approach, they are inherently limited in meeting the heterogeneity of needs facing families with young children living in poverty. An alternative approach, of course, is to address inequality of resources and opportunity directly by offering cash payments to families (similar to the monthly stimulus checks families are receiving monthly as part of the pandemic relief legislation). A new study will tell us how large such payments need to be for positive impacts on infants and toddlers (Baby's First Years, 2021). However, research to date finds that these programs can be expensive and impacts on children, while positive, are modest-a $\$ 1000$ increase in a family's annual income increases children's achievement by only $~ 5-6 \%$ of a standard deviation (Duncan et al., 2011).

Fortunately, because there is a growing recognition that families in need are not in siloed systems (and indeed that cross-disciplinary solutions are needed), the field has evolved to include multi-platform approaches, some of which are tiered like the Smart Beginnings model described above. There are currently a number of multi-level, multiplatform initiatives initiated during early childhood across the US aiming for broad community-level impact (e.g., the New York City Council's City's First Readers Initiative, ${ }^{1}$ Get Ready Guilford in North Carolina, ${ }^{2}$ First 5 California, ${ }^{3}$ NYC Health + Hospitals 3-2-1 IMPACT, the Pediatric Public Health Initiative in Flint, Michigan, ${ }^{4}$ and Together Growing Strong in New York City ${ }^{5}$ ). All of these initiatives include a commitment to a cross-sector model with implications for child health and development. But what Smart Beginnings brings to the table is a way to efficiently and effectively support the school readiness of a large number of low-income families by attending to barriers to engagement among families and the limited time and resources city and state agencies have to deliver such care. Embedding a tiered model in a universally-accessible platform like pediatric care (and other health care sites), and strategically offering home visiting to families that need it most, Smart Beginnings promises to

\footnotetext{
${ }_{1}^{1}$ https://www.readthecity.org/

2 https://www.getreadyguilford.org/

${ }^{3}$ https://www.first5california.com/

${ }^{4}$ https://msuhurleypphi.org/

5 https://med.nyu.edu/departments-institutes/population-health/divis ions-sections-centers/health-behavior/together-growing-strong
}

offer the field a new model for addressing school readiness disparities of children in poverty.

Funding The work was financially supported by National Institute of Child Health and Human Development (Grant No. HD076390).

\section{Declarations}

Conflict of interest The authors have no relevant financial or non-financial interests to disclose.

Ethical approval Findings reported on from the Smart Beginnings Trial were performed in accordance with the ethical standards of the 1964 Helsinki Declaration and later amendments and approved by the Internal Review Boards at the University of Pittsburgh and New York University.

\section{References}

Altonji, J. G., \& Blank, R. M. (1999). Race and gender in the labor market. In R. C. Ashenfelter \& D. Card (Eds.), Handbook of labor economics (Vol. 3, pp. 3143-3259). North Holland: Elsevier. https://doi.org/10.1016/S1573-4463(99)30039-0

American Academy of Pediatrics (2021). 2021 periodicity schedule. Retrieved July 26, 2021 from https://www.aap.org/en-us/profe ssional-resources/practice-transformation/managing-patients/ Pages/Periodicity-Schedule.aspx

Asarnow, J. R., Kolko, D. J., Miranda, J., \& Kazak, A. E. (2017). The pediatric patient-centered medical home: Innovative models for improving behavioral health. American Psychologist, 72(1), 13-27. https://doi.org/10.1037/a0040411

Ashby, B. D., Ehmer, A. C., \& Scott, S. M. (2019). Trauma-informed care in a patient-centered medical home for adolescent mothers and their children. Psychological Services, 16(1), 67-74. https:// doi.org/10.1037/ser0000315

Baby's First Years (2021). Retrieved July 28, 2021 from https://www. babysfirstyears.com

Bailey, Z. D., Krieger, N., Agénor, M., Graves, J., Linos, N., \& Bassett, M. T. (2017). Structural racism and health inequities in the USA: Evidence and interventions. Lancet (london, England), 389(10077), 1453-1463. https://doi.org/10.1016/S01406736(17)30569-X

Baumrind, D. (1971). Current patterns of parental authority. Developmental Psychology, 4(1, Pt.2), 1-103. https://doi.org/10.1037/ h0030372

Bell, R. Q. (1968). A reinterpretation of the direction of effects in studies of socialization. Psychological Review, 75(2), 81-95. https:// doi.org/10.1037/h0025583

Belsky, J. (1984). The determinants of parenting: A process model. Child Development, 55(1), 83-96. https://doi.org/10.2307/11298 36

Berkule, S. B., Cates, C. B., Dreyer, B. P., Huberman, H. S., Arevalo, J., Burtchen, N., Weisleder, A., \& Mendelsohn, A. L. (2014). Reducing maternal depressive symptoms through promotion of parenting in pediatric primary care. Clinical Pediatrics, 53(5), 460-469. https://doi.org/10.1177/0009922814528033

Blair, C. (2002). School readiness: Integrating cognition and emotion in a neurobiological conceptualization of children's functioning at school entry. American Psychologist, 57(2), 111-127. https:// doi.org/10.1037/0003-066X.57.2.111 
Blair, C. (2010). Stress and the development of self-regulation in context. Child Development Perspectives, 4(3), 181-188. https://doi. org/10.1111/j.1750-8606.2010.00145.x

Bornstein, M. H., Tamis-Lemonda, C. S., Hahn, C. S., \& Haynes, O. M. (2008). Maternal responsiveness to young children at three ages: Longitudinal analysis of a multidimensional, modular, and specific parenting construct. Developmental Psychology, 44(3), 867-874. https://doi.org/10.1037/0012-1649.44.3.867

Bower, K. M., Nimer, M., West, A. L., \& Gross, D. (2020). Parent involvement in maternal, infant, and early childhood home visiting programs: An integrative review. Prevention Science, 21, 728-747. https://doi.org/10.1007/s11121-020-01129-z

Briggs, R. (2021). Zero to Three, personal communication.

Brody, G. H., Chen, Y. F., Murry, V. M., Ge, X., Simons, R. L., Gibbons, F. X., Gerrard, M., \& Cutrona, C. E. (2006). Perceived discrimination and the adjustment of African American youths: A five-year longitudinal analysis with contextual moderation effects. Child Development, 77(5), 1170-1189. https://doi.org/ 10.1111/j.1467-8624.2006.00927.x

Canfield, C., Miller, E.B., Shaw, D., Morris, P., \& Mendelsohn, A. (2020a, May 4). Increasing reach of preventive programs through a tiered approach tailored to heterogeneity in risk. To have been presented at the Pediatric Academic Societies Annual Meeting. (conference canceled)

Canfield, C. F., Miller, E. B., Shaw, D. S., Morris, P., Alonso, A., \& Mendelsohn, A. L. (2020b). Beyond language: Impacts of shared reading on parenting stress and early parent-child relational health. Developmental Psychology, 56(7), 1305-1315. https:// doi.org/10.1037/dev0000940

Canfield, C. F., Weisleder, A., Cates, C. B., Huberman, H. S., Dreyer, B. P., Legano, L. A., Johnson, S. B., Seery, A., \& Mendelsohn, A. L. (2015). Primary care parenting intervention and its effects on the use of physical punishment among low-income parents of toddlers. Journal of Developmental and Behavioral Pediatrics, 36(8), 586-593. https://doi.org/10.1097/DBP.0000000000 000206

Cates, C. B., Weisleder, A., Dreyer, B. P., Johnson, S. B., Vlahovicova, K., Ledesma, J., \& Mendelsohn, A. L. (2016a). Leveraging healthcare to promote responsive parenting: Impacts of the video interaction project on parenting stress. Journal of Child and Family Studies, 25(3), 827-835. https://doi.org/10.1007/ s10826-015-0267-7

Cates, C. B., Weisleder, A., \& Mendelsohn, A. L. (2016b). Mitigating the effects of family poverty on early child development through parenting interventions in primary care. Academic Pediatrics, 16(3 Suppl), S112-S120. https://doi.org/10.1016/j.acap.2015. 12.015

Cicchetti, D., \& Rogosch, F. A. (1996). Equifinality and multifinality in developmental psychopathology. Development and Psychopathology, 8(4), 597-600. https://doi.org/10.1017/S095457940 0007318

Cicchetti, D., \& Toth, S. L. (2009). The past achievements and future promises of developmental psychopathology: The coming of age of a discipline. Journal of Child Psychology and Psychiatry, and Allied Disciplines, 50(1-2), 16-25. https://doi.org/10.1111/j. 1469-7610.2008.01979.x

Cohen, R. A., Terlizzi, E. P., Cha, A. E., \& Martinez, M. E. (2020). Health insurance coverage: Early release of estimates from the national health interview survey. Retrieved January-June, 2020 from https://www.cdc.gov/nchs/data/nhis/earlyrelease/insur 202102-508.pdf

Dahl, G. B., \& Lochner, L. (2012). The impact of family income on child achievement: Evidence from the earned income tax credit. American Economic Review, 102(5), 1927-1956. https://doi.org/ 10.1257/aer.102.5.1927
Dalziel, K., \& Segal, L. (2012). Home visiting programmes for the prevention of child maltreatment: Cost-effectiveness of 33 programmes. Archives of Disease in Childhood, 97(9), 787-798. https://doi.org/10.1136/archdischild-2011-300795

Dearing, J. W. (2008). Evolution of diffusion and dissemination theory. Journal of Public Health Management and Practice: JPHMP, 14(2), 99-108. https://doi.org/10.1097/01.PHH.0000311886. 98627.b7

Desmond, M., \& Emirbayer, M. (2009). What is racial domination? Du Bois Review, 6(2), 335-355. https://doi.org/10.1017/S1742 058X09990166

Dishion, T. J., Shaw, D., Connell, A., Gardner, F., Weaver, C., \& Wilson, M. (2008). The family check-up with high-risk indigent families: Preventing problem behavior by increasing parents' positive behavior support in early childhood. Child Development, 79(5), 1395-1414. https://doi.org/10.1111/j.1467-8624.2008.01195.x

Dodge, K. A., Goodman, W. B., Murphy, R. A., O’Donnell, K., Sato, J., \& Guptill, S. (2014). Implementation and randomized controlled trial evaluation of universal postnatal nurse home visiting. American Journal of Public Health, 104(Suppl 1), S136-S143. https://doi.org/10.2105/AJPH.2013.301361

Dodge, K. A., Malone, P. S., Lansford, J. E., Miller, S., Pettit, G. S., $\&$ Bates, J. E. (2009). A dynamic cascade model of the development of substance-use onset. Monographs of the Society for Research in Child Development, 74(3), vii-119. https://doi.org/ 10.1111/j.1540-5834.2009.00528.x

Doyle, S., Chavez, S., Cohen, S., and Morrison, S. Fostering social and emotional health through pediatric primary care: Common threads to transform practice and systems. Center for the Study of Social Policy. Retrieved September, 2019 from https://CSSP. org/resource/pspprogram-analysis-report/

Dudek, E., Henschen, E., Finkle, E., Vyas, S., Fiszbein, D., \& Shukla, A. (2018). Improving continuity in a patient centered medical home. Pediatrics, 142, 1. https://doi.org/10.1542/peds.142.1 MeetingAbstract.366

Duncan, G. J., Dowsett, C. J., Claessens, A., Magnuson, K., Huston, A. C., Klebanov, P., Pagani, L. S., Feinstein, L., Engel, M., BrooksGunn, J., Sexton, H., Duckworth, K., \& Japel, C. (2007). School readiness and later achievement. Developmental Psychology, 43(6), 1428-1446. https://doi.org/10.1037/0012-1649.43.6.1428

Duncan, G. J., Morris, P. A., \& Rodrigues, C. (2011). Does money really matter? Estimating impacts of family income on young children's achievement with data from random-assignment experiments. Developmental Psychology, 47(5), 1263-1279. https:// doi.org/10.1037/a0023875

Duncan, G., Yeung, W., Brooks-Gunn, J., \& Smith, J. (1998). How much does childhood poverty affect the life chances of children? American Sociological Review, 63(3), 406-423.

Eisenberg, N., Valiente, C., \& Eggum, N. D. (2010). Self-regulation and school readiness. Early Education and Development, 21(5), 681-698. https://doi.org/10.1080/10409289.2010.497451

Emery, R. E. (1988). Marriage, divorce, and children's adjustment. Newbury Park. Sage Publications. http://www.loc.gov/catdir/ enhancements/fy0654/87026502-t.html

Evans, G. W., \& Kim, P. (2013). Childhood poverty, chronic stress, self-regulation, and coping. Child Development Perspectives, 7(1), 43-48. https://doi.org/10.1111/cdep.12013

Fletcher, R. W., \& Fletcher, S. W. (2005). Clinical epidemiology: The essentials (4th ed.). Lippincott, Williams \& Wilkins.

Garner, A., Yogman, M., \& Committee on Psychosocisal Aspects of Child and Family Health, Section on Developmental and Behavioral Pediatrics, Council on Early Childhood. (2021). Preventing childhood toxic stress: Partnering with families and communities to promote relational health. Pediatrics, 148(2), e2021052582.

Gennetian, L. A., Castells, N., \& Morris, P. (2010). Meeting the basic needs of children: Does income matter? Children and Youth 
Services Review, 32(9), 1138-1148. https://doi.org/10.1016/j. childyouth.2010.03.004

Ghate, D. (2016). From programs to systems: Deploying implementation science and practice for sustained real world effectiveness in services for children and families. Journal of Clinical Child and Adolescent Psychology, 45(6), 812-826. https://doi.org/10. 1080/15374416.2015.1077449

Goodman, W. B., Dodge, K. A., Bai, Y., O’Donnell, K. J., \& Murphy, R. A. (2019). Randomized controlled trial of family connects: Effects on child emergency medical care from birth to 24 months. Development and Psychopathology, 31(5), 1863-1872. https:// doi.org/10.1017/S0954579419000889

Greenberg, M. T., \& Abenavoli, R. (2017). Universal interventions: Fully exploring their impacts and potential to produce population-level impacts. Journal of Research on Educational Effectiveness, 10(1), 40-67. https://doi.org/10.1080/19345747. 2016.1246632

Hails, K. A., Zhou, Y., \& Shaw, D. S. (2019). The mediating effect of self-regulation in the association between poverty and child weight: A systematic review. Clinical Child and Family Psychology Review, 22, 290-315. https://doi.org/10.1007/ s10567-019-00279-z

Hale, L., Berger, L. M., LeBourgeois, M. K., \& Brooks-Gunn, J. (2009). Social and demographic predictors of preschoolers' bedtime routines. Journal of Developmental and Behavioral Pediatrics, 30(5), 394-402. https://doi.org/10.1097/DBP.0b013 e3181ba0e64

Harding, K., Galano, J., Martin, J., Huntington, L., \& Schellenbach, C. J. (2007). Healthy families America ${ }^{\circledR}$ effectiveness: A comprehensive review of outcomes. Journal of Prevention \& Intervention in the Community, 34(1-2), 149-179. https://doi. org/10.1300/J005v34n0108

Harris, P. L. (2006). Conversation, pretense, and theory of mind. In J. W. Astington \& J. A. Baird (Eds.), Why language matters for theory of mind. University Press.

Hart, B., \& Risley, T. R. (1995). Meaningful differences in the everyday experience of young American children. Paul Brookes Publishing Company.

Hartz, K., \& Williford, A. (2015). Child negative emotionality and caregiver sensitivity across context: Links with children's kindergarten behaviour problems. Infant and Child Development, 24, 107-129. https://doi.org/10.1002/icd.1887

Healthy Steps (2021). Transforming the promise of pediatric primary care. Retrieved July 28, 2021 from www.healthysteps.org

High, P. C., LaGasse, L., Becker, S., Ahlgren, I., \& Gardner, A. (2000). Literacy promotion in primary care pediatrics: Can we make a difference? Pediatrics, 105(4 Pt 2), 927-934.

Hill, H. D., Morris, P., Gennetian, L. A., Wolf, S., \& Tubbs, C. (2013). The consequences of income instability for children's well-being. Child Development Perspectives, 7, 85-90. https:// doi.org/10.1111/cdep. 12018

Hoff-Ginsberg, E. (1991). Mother-child conversation in different social classes and communicative settings. Child Development, 62(4), 782-796. https://doi.org/10.2307/1131177

HomVEE. (2020). Early childhood home visiting models reviewing evidence of effectiveness OPRE Report \#2020-126. Retrieved July 20, 2021 from https://homvee.acf.hhs.gov/sites/default/ files/2020-12/HomVEE_Summary_Brief.pdf

Huttenlocher, J., Waterfall, H., Vasilyeva, M., Vevea, J., \& Hedges, L. V. (2010). Sources of variability in children's language growth. Cognitive Psychology, 61(4), 343-365. https://doi. org/10.1016/j.cogpsych.2010.08.002

Isaacs, J. \& Roessel, E. (2008). Research Brief \#3: Early Head Start. Impacts of Early Childhood Programs: Brookings Institute. Retrieved July 15, 2021 from https://www.brookings.edu/wpcontent/uploads/2016/07/09_early_programs_brief3.pdf
Jimenez, M. E., Mendelsohn, A. L., Lin, Y., Shelton, P., \& Reichman, N. (2019). Early shared reading is associated with less harsh parenting. Journal of Developmental and Behavioral Pediatrics, 40(7), 530-537. https://doi.org/10.1097/DBP.0000000000 000687

Justvig, S. P., Li, J., Carvella, G., Chen, M., Wang, H., Benz Scott, L. A., \& Pati, S. (2017). Improving adherence to care recommendations using a community health worker intervention with the pediatric medical home. Journal of Community Health, 42, 444-452. https://doi.org/10.1007/s10900-016-0275

Kazak, A. E., Nash, J. M., Hiroto, K., \& Kaslow, N. J. (2017). Psychologists in patient-centered medical homes (PCMHs): Roles, evidence, opportunities, and challenges. American Psychologist, 72(1), 1-12. http://dx.doi.org/https://doi.org/10.1037/ a0040382. https://psycnet.apa.org/fulltext/2016-62373-001. html

Kenney, G. M., Haley, J., Pan, C., Lynch, V., \& Buettgens, M. (2016). Children's coverage climb continues: Uninsurance and medicaid/ CHIP eligibility and participation under the ACA. Urban Institute. Retrieved July 29, 2021 from https://www.urban.org/ sites/default/files/publication/80536/2000787-Childrens-Cover age-Climb-Continues-Uninsurance-and-Medicaid-CHIP-Eligi bility-and-Participation-Under-the-ACA.pdf

Klass, P., Needleman, R., \& Zuckerman, B. (1999). Reach out and read program manual (2nd ed.). Boston Medical Center.

Kuklinski, M. R., Crowley, D. M., Dishion, T. J., Wilson, M. N., Pelham, W. E., \& Shaw, D. S. (2020). Supporting strategic investment in social programs: A cost analysis of the family check-up. Prevention Science, 21(2), 256-267. https://doi.org/10.1007/ s11121-019-01077-3

Ladd, G. W., Birch, S. H., \& Buhs, E. S. (1999). Children's social and scholastic lives in kindergarten: Related spheres of influence? Child Development, 70(6), 1373-1400. https://doi.org/10.1111/ 1467-8624.00101

Landry, S. H., Smith, K. E., \& Swank, P. R. (2006). Responsive parenting: Establishing early foundations for social, communication, and independent problem-solving skills. Developmental Psychology, 42(4), 627-642. https://doi.org/10.1037/0012-1649.42.4.627

Landry, S. H., Smith, K. E., Swank, P. R., \& Guttentag, C. (2008). A responsive parenting intervention: The optimal timing across early childhood for impacting maternal behaviors and child outcomes. Developmental Psychology, 44(5), 1335-1353. https:// doi.org/10.1037/a0013030

Leve, L. D., Harold, G. T., Ge, X., Neiderhiser, J. M., Shaw, D., Scaramella, L. V., \& Reiss, D. (2009). Structured parenting of toddlers at high versus low genetic risk: Two pathways to child problems. Journal of the American Academy of Child and Adolescent Psychiatry, 48(11), 1102-1109. https://doi.org/10.1097/CHI.0b013 e3181b8bfc0

Leve, L. D., Kerr, D. C., Shaw, D., Ge, X., Neiderhiser, J. M., Scaramella, L. V., Reid, J. B., Conger, R., \& Reiss, D. (2010). Infant pathways to externalizing behavior: Evidence of genotype $\mathrm{x}$ environment interaction. Child Development, 81(1), 340-356. https:// doi.org/10.1111/j.1467-8624.2009.01398.x

Levenstein, P., Levenstein, S., \& Oliver, D. (2002). First grade school readiness of former child participants in a South Carolina replication of the parent-child home program. Journal of Applied Developmental Psychology, 23(3), 331-353.

Limbers, C. A., Gutierrez, A., \& Adelyn Cohen, L. (2020). The patientcentered medical home: Mental health and parenting stress in mothers of children with autism. Journal of Primary Care and Health. https://doi.org/10.1177/2150132720936067

Liu, P., Kryski, K. R., Smith, H. J., Joanisse, M. F., \& Hayden, E. P. (2020). Transactional relations between early child temperament, structured parenting, and child outcomes: A three-wave 
longitudinal study. Development and Psychopathology, 32(3), 923-933. https://doi.org/10.1017/S0954579419000841

Love, J. M., Chazan-Cohen, R., Raikes, H., \& Brooks-Gunn, J. (2013). What makes a difference: Early head start evaluation findings in a developmental context. Monographs of the Society for Research in Child Development, 78(1), vii-173. https://doi.org/10.1111/j. 1540-5834.2012.00699.x

Love, J. M., Kisker, E. E., Ross, C., Raikes, H., Constantine, J., Boller, K., Brooks-Gunn, J., Chazan-Cohen, R., Tarullo, L. B., BradySmith, C., Fuligni, A. S., Schochet, P. Z., Paulsell, D., \& Vogel, C. (2005). The effectiveness of early head start for 3-year-old children and their parents: Lessons for policy and programs. Developmental Psychology, 41(6), 885-901. https://doi.org/10. 1037/0012-1649.41.6.88

Mendelsohn, A. L., Cates, C. B., Weisleder, A., Berkule Johnson, S., Seery, A. M., Canfield, C. F., Huberman, H. S., \& Dreyer, B. P. (2018). Reading aloud, play, and social-emotional development. Pediatrics, 141(5), e20173393. https://doi.org/10.1542/ peds.2017-3393

Mendelsohn, A. L., Dreyer, B. P., Flynn, V., Tomopoulos, S., Rovira, I., Tineo, W., Pebenito, C., Torres, C., Torres, H., \& Nixon, A. F. (2005). Use of videotaped interactions during pediatric well-child care to promote child development: A randomized, controlled trial. Journal of Developmental and Behavioral Pediatrics, 26(1), 34-41.

Mendelsohn, A. L., Mogilner, L. N., Dreyer, B. P., Forman, J. A., Weinstein, S. C., Broderick, M., Cheng, K. J., Magloire, T., Moore, T., \& Napier, C. (2001). The impact of a clinic-based literacy intervention on language development in inner-city preschool children. Pediatrics, 107(1), 130-134. https://doi.org/10.1542/ peds.107.1.130

Miller, E. B., Canfield, C. F., Morris, P. A., Shaw, D. S., Cates, C. B., \& Mendelsohn, A. L. (2020). Sociodemographic and psychosocial predictors of VIP attendance in smart beginnings through 6 months: Effectively targeting at-risk mothers in early visits. Prevention Science: THe Official Journal of the Society for Prevention Research, 21(1), 120-130. https://doi.org/10.1007/ s11121-019-01044-y

Milligan, K., \& Stabile, M. (2011). Do child tax benefits affect the well-being of children? Evidence from Canadian child benefit expansions. American Economic Journal: Economic Policy, 3(3), 175-205. https://doi.org/10.1257/pol.3.3.175

Minkovitz, C. S., Hughart, N., Strobino, D., Scharfstein, D., Grason, H., Hou, W., Miller, T., Bishai, D., Augustyn, M., McLearn, K. T., \& Guyer, B. (2003). A practice-based intervention to enhance quality of care in the first 3 years of life: The healthy steps for young children program. Journal of the American Medical Association, 290(23), 3081-3091. https://doi.org/10.1001/jama.290. 23.3081

Minkovitz, C. S., Strobino, D., Mistry, K. B., Scharfstein, D. O., Grason, H., Hou, W., Ialongo, N., \& Guyer, B. (2007). Healthy steps for young children: Sustained results at 5.5 years. Pediatrics, 120(3), e658-e668. https://doi.org/10.1542/peds.2006-1205

Mohajer, N., \& Earnest, J. (2010). Widening the aim of health promotion to include the most disadvantage: Vulnerable adolescents and the social determinants of health. Health Education Research, 25(3), 387-394. https://doi.org/10.1093/her/cyq016

Morris, P., Bierman, K., Harding, J., \& Gennetian, L. (2015). Evidence for investing in parenting programs. Commissioned report for the IOM/NRC Committee on Supporting the Parents of Young Children. [Unpublished manuscript].

National Home Visiting Resource Center. (2020). Who is being served? By evidence-based methods. Retrieved July 25, 2021 from https:// nhvrc.org/state_profile/national-profile-2020/
National Head Start Association (2021a). National Head Start Facts Sheets. Retrieved July 28, 2021 from https://www.nhsa.org/natio nal-head-start-fact-sheets/

National Head Start Association. (2021b). National Head Start Association: Fact. Administration on children, youth and families. Retrieved July 28, 2021 from https://www.nhsa.org/natio nal-head-start-fact-sheets/

National Academies and of Sciences, Engineering, and Medicine. (2016). Division of behavioral and social sciences and education, board on children, youth, and families, committee on supporting the parents of young children. In H. Breiner, M. Ford, \& V. L. Gadsden (Eds.), Parenting matters supporting parents of children ages 0-8. National Academies Press (US).

Needlman, R., Toker, K. H., Dreyer, B. P., Klass, P., \& Mendelsohn, A. L. (2005). Effectiveness of a primary care intervention to support reading aloud: A multicenter evaluation. Ambulatory Pediatrics : THe Official Journal of the Ambulatory Pediatric Association, 5(4), 209-215. https://doi.org/10.1367/A04-110R.1

Neuman, S. B. (1991). Guiding young children's participation in early literacy development: A family literacy program for adolescent mothers. Early Child Development and Care, 127(1), 119-129. https://doi.org/10.1080/0300443971270110

New York Department of Health. (2021). First 1000 days on Medicaid initiative. Retrieved July 28, 2021 from https://www.Health.ny. gov/health_care/Medicaid/redesign/first_1000.htm

Normandeau, S., \& Guay, F. (1998). Preschool behavior and first-grade school achievement: The mediational role of cognitive self-control. Journal of Educational Psychology, 90(1), 111-121. https:// doi.org/10.1037/0022-0663.90.1.111

Office of Head Start. (2017). Head start program fact sheet. Retrieved March 15, 2021 from https://eclkc.ohs.acf.hhs.gov/about-us/artic le/head-start-program-facts-fiscal-year-2017

Olds, D. L., Henderson, C. R., Jr., Chamberlin, R., \& Tatelbaum, R. (1986). Preventing child abuse and neglect: A randomized trial of nurse home visitation. Pediatrics, 78(1), 65-78.

Olds, D., Henderson, C. R., Jr., Cole, R., Eckenrode, J., Kitzman, H., Luckey, D., Pettitt, L., Sidora, K., Morris, P., \& Powers, J. (1998). Long-term effects of nurse home visitation on children's criminal and antisocial behavior: 15-year follow-up of a randomized controlled trial. Journal of the American Medical Association, 280(14), 1238-1244. https://doi.org/10.1001/jama.280.14.1238

Pachter, L. M., \& Coll, C. G. (2009). Racism and child health: A review of the literature and future directions. Journal of Developmental and Behavioral Pediatrics, 30(3), 255-263. https://doi.org/10. 1097/DBP.0b013e3181a7ed5a

Patterson, G. R. (1982). A social learning approach: 3. Coercive family process. Castalia.

Pelham, W. E., 3rd., Dishion, T. J., Tein, J. Y., Shaw, D. S., \& Wilson, M. N. (2017). What doesn't work for whom? Exploring heterogeneity in responsiveness to the family check-up in early childhood using a mixture model approach. Prevention Science, 18(8), 911-922. https://doi.org/10.1007/s11121-017-0805-1

Perlman, S., Cowan, B., Gewirtz, A., Haskett, M., \& Stokes, L. (2012). Promoting positive parenting in the context of homelessness. American Journal of Orthopsychiatry, 82(3), 402-412. https:// doi.org/10.1111/j.1939-0025.2012.01158.x

Ramos-Gomez, F. J., \& Shepard, D. S. (1999). Cost-effectiveness model for prevention of early childhood caries. Journal of the California Dental Association, 27(7), 539-544.

Razza, R. A., Martin, A., \& Brooks-Gunn, J. (2010). Associations among family environment, sustained attention, and school readiness for low-income children. Developmental Psychology, 46(6), 1528-1542. https://doi.org/10.1037/a0020389

Reach Out and Read National Center. (2021). Organizational structure of Reach Out and Read Retrieved from https://www.reachoutan dread.org/about/affiliates/ 
Roby, E., Miller, E., Shaw, D., Morris, P., Gill, A., Bogen, D., Rosas, J., Canfield, C., Hails, K., Wippick, H., Honoroff, J., Cates, C., Weisleder, A., Chadwick, K., Raak, C., \& Mendelsohn, A. (2021). Improving parent-child interactions through pediatrics: A two-site randomized controlled trial. Pediatrics. https://doi. org/10.1542/peds.2020-1799

Romano, E., Babchishin, L., Pagani, L. S., \& Kohen, D. (2010). School readiness and later achievement: Replication and extension using a nationwide Canadian survey. Developmental Psychology, 46(5), 995-1007. https://doi.org/10.1037/a0018880

Sameroff, A. J., \& Chandler, M. J. (1975). Reproductive risk and the continuum of caretaking casualty. Review of Child Development Research, 4, 187-244.

Scaramella, L. V., \& Leve, L. D. (2004). Clarifying parent-child reciprocities during early childhood: The early childhood coercion model. Clinical Child and Family Psychology Review, 7(2), 89-107. https://doi.org/10.1023/B:CCFP.0000030287. 13160.a3

Shaw, D. S., \& Bell, R. Q. (1993). Developmental theories of parental contributors to antisocial behavior. Journal of Abnormal Child Psychology, 21(5), 493-518. https://doi.org/10.1007/BF009 16316

Shaw, D. S., Bell, R. Q., \& Gilliom, M. (2000). A truly early starter model of antisocial behavior revisited. Clinical Child and Family Psychology Review, 3(3), 155-172. https://doi.org/10.1023/a: 1009599208790

Shaw, D. S., Connell, A., Dishion, T. J., Wilson, M. N., \& Gardner, F. (2009). Improvements in maternal depression as a mediator of intervention effects on early childhood problem behavior. Development and Psychopathology, 21(2), 417-439. https://doi.org/10. 1017/S0954579409000236

Shaw, D. S., Dishion, T. J., Supplee, L., Gardner, F., \& Arnds, K. (2006). Randomized trial of a family-centered approach to the prevention of early conduct problems: 2 -year effects of the family check-up in early childhood. Journal of Consulting and Clinical Psychology, 74(1), 1-9. https://doi.org/10.1037/0022-006X. 74.1.1

Shaw, D. S., Winslow, E. B., Owens, E. B., Vondra, J. I., Cohn, J. F., \& Bell, R. Q. (1998). The development of early externalizing problems among children from low-income families: A transformational perspective. Journal of Abnormal Child Psychology, 26(2), 95-107. https://doi.org/10.1023/A:1022665704584

Shonkoff, J. P. (2017). Rethinking the definition of evidence-based interventions to promote early childhood development. Pediatrics, 140(6), e20173136. https://doi.org/10.1542/peds.2017-3136

Sitnick, S. L., Shaw, D. S., Gill, A., Dishion, T., Winter, C., Waller, R., Gardner, F., \& Wilson, M. (2015). Parenting and the family check-up: Changes in observed parent-child interaction following early childhood intervention. Journal of Clinical Child and Adolescent Psychology, 44(6), 970-984. https://doi.org/10.1080/ 15374416.2014.940623

Sparr, M., Zaid, S., Filene, J., \& Denmark, N. (2017). Engaging parents in early head start home-based programs: How do home visitors do this? Journal of Evidence-Informed Social Work., 14(5), 329-359. https://doi.org/10.1080/23761407.2017.1302858

Spoth, R., Clair, S., Greenberg, M., Redmond, C., \& Shin, C. (2007). Toward dissemination of evidence-based family interventions: Maintenance of community-based partnership recruitment results and associated factors. Journal of Family Psychology, 21(2), 137-146. https://doi.org/10.1037/0893-3200.21.2.137

Spoth, R., Redmond, C., Hockaday, C., \& Shin, C. Y. (1996). Barriers to participation in family skills preventive interventions and their evaluations: A replication and extension. Family Relations: An Interdisciplinary Journal of Applied Family Studies, 45(3), 247-254. https://doi.org/10.2307/585496

Tabors, P. O., Roach, K. A., \& Snow, C. E. (2001). Home language and literacy environment: Final results. In D. K. Dickinson \&
P. O. Tabors (Eds.), Beginning literacy with language: Young children learning at home and school (pp. 111-138). Paul $\mathrm{H}$ Brookes Publishing.

Taraban, L., \& Shaw, D. S. (2018). Parenting in context: Revisiting Belsky's classic process of parenting model in early childhood. Developmental Review, 48, 55-81. https://doi.org/10.1016/j.dr. 2018.03.006

Tiberio, S. S., Capaldi, D. M., Kerr, D. C., Bertrand, M., Pears, K. C., \& Owen, L. (2016). Parenting and the development of effortful control from early childhood to early adolescence: A transactional developmental model. Development and Psychopathology, 28(3), 837-853. https://doi.org/10.1017/S0954579416000341

Tomaskovic-Devey, D., Thomas, M., \& Johnson, K. (2005). Race and the accumulation of human capital across the career: A theoretical model and fixed-effects application. American Journal of Sociology, 111(1), 58-89. https://doi.org/10.1086/431779

Turner, M.A. \& Skidmore, F. (1999). Mortgage Lending Discrimination: A Review of Existing Evidence. The Urban Institute. Retrieved from https://www.urban.org/sites/default/files/publi cation/66151/309090-Mortgage-Lending-Discrimination.PDF

Wagner, M., Spiker, D., \& Linn, M. I. (2002). The effectiveness of the parents as teachers program with low-income parents and children. Topics in Early Childhood Special Education, 22(2), 67-81. https://doi.org/10.1177/02711214020220020101

Weisleder, A., Cates, C. B., Dreyer, B. P., Berkule Johnson, S., Huberman, H. S., Seery, A. M., Canfield, C. F., \& Mendelsohn, A. L. (2016). Promotion of positive parenting and prevention of socioemotional disparities. Pediatrics, 137(2), e20153239. https:// doi.org/10.1542/peds.2015-3239

Weisleder, A., Cates, C. B., Harding, J. F., Johnson, S. B., Canfield, C. F., Seery, A. M., Raak, C. D., Alonso, A., Dreyer, B. P., \& Mendelsohn, A. L. (2019). Links between shared reading and play, parent psychosocial functioning, and child behavior: Evidence from a randomized controlled trial. Journal of Pediatrics, 213, 187-195.e1. https://doi.org/10.1016/j.jpeds.2019.06.037

Western, B., Bloome, D., Sosnaud, B., \& Tach, L. M. (2016). Trends in income insecurity among U.S. children 1984-2010. Demography, 53(2), 419-447. https://doi.org/10.1007/s13524-016-0463-0

Whitehurst, G. J., Arnold, D. S., Epstein, J. N., Angell, A. L., Smith, M., \& Fischel, J. E. (1994). A picture book reading intervention in day care and home for children from low-income families. Developmental Psychology, 30(5), 679-689. https://doi.org/10. 1037/0012-1649.30.5.679

Whitehurst, G. J., Zevenbergen, A. A., Crone, D. A., Schultz, M. D., Velting, O. N., \& Fischel, J. E. (1999). Outcomes of an emergent literacy intervention from head start through second grade. Journal of Educational Psychology, 91(2), 261.

Wolf, E. R., Hochheimer, C. J., Sabo, R. T., DeVoe, J., Wasserman, R., Geissai, E., Opel, D. J., Warren, N., Puro, J., O’Neil, J., Pecsok, J., \& Krist, A. H. (2018). Gaps in well-child care attendance among primary care clinics serving low-income families. Pediatrics, 142(5), e20174019. https://doi.org/10.1542/peds.2017-4019

Young, M. E. (2014). Addressing and mitigating vulnerability across the life cycle: The case for investing in early childhood. United Nations Development Program Human Development Report Office, Occasional Paper.

Zuckerman, B. (2009). Promoting early literacy in pediatric practice: Twenty years of reach out and read. Pediatrics, 124(6), 1660 1665. https://doi.org/10.1542/peds.2009-1207

Publisher's Note Springer Nature remains neutral with regard to jurisdictional claims in published maps and institutional affiliations. 